\title{
PHASE FORMATION DURING NONEQUILIBRIUM CRYSTALLIZATION OF Al-Mg-Si SYSTEM ALLOYS
}

\author{
V. M. Zamyatin and K. Yu. Shmakova
}

UDC 669.7.018.672

Nonequilibrium crystallization of alloys of the Al-Mg-Si system, and also their structure and phase composition in a cast condition are studied. Thermal analysis is used to establish phase transformation temperature ranges, occurring during nonequilibrium crystallization of industrial aluminum alloys AD31 and AD33. $x$-Ray microanalysis is used to determine metastable phase composition in the alloys in a cast condition. Keywords: aluminum alloys, nonequilibrium crystallization, thermogram, x-ray microanalysis, phase composition.

The structure and properties of aluminum alloy semifinished products depend to a considerable extent on original ingot structure. Industrial experience shows that during ingot deformation there is often crack formation. Cracked ingots as waste products are used again in alloy preparation. In the course of performing each melting there is formation of much slag, which is a technogenic product. The amount of slag increases from melt to melt, and this leads to unrecoverable loss of aluminum and alloying elements. The inadequate quality of ingots is caused by imperfection of alloy preparation technology and their crystallization conditions. Therefore a scientifically based approach is required for improving alloy preparation technology and ingot manufacture [1,2]. Under actual production conditions for aluminum alloy ingots melt crystallization occurs under nonequilibrium conditions. In view of this, a study of nonequilibrium crystallization of aluminum alloys, in particular, multicomponent alloys, is an important task for metallurgical production. Results are presented in this article for study of nonequilibrium crystallization of alloys AD31 and AD33 of the Al-Mg-Si system, and also their structure and phase composition in a cast condition.

Specimens studied were selected from industrial ingots $370 \mathrm{~mm}$ in diameter of alloy AD31 and $190 \mathrm{~mm}$ in diameter of alloy AD33, cast by a semicontinuous method. Alloy chemical composition is provided in Table 1 . Alloy crystallization was carried out by a thermal analysis (TA) method, followed by numerical differentiation with respect to time for cooling curves. The thermogram obtained was used to find the values of alloy liquidus and solidus temperatures, and also phase transformations in the crystallization range with a specimen controlled cooling rate.

In order to study structure and phase composition in alloys, a JSM-5900 LV scanning electron microscope was used with an electron probe microanalyzer attachment. The microanalyzer spot is 1-2 $\mu \mathrm{m}$. In order to obtain reliable experimental data, local chemical composition was only studied for three phases, whose linear dimension exceeded 7-10 $\mu \mathrm{m}$.

Thermograms were plotted from analysis results for specimens of alloys AD31 and AD33. In a cooling thermogram for an alloy AD31 specimen (Fig. 1a), there are three isothermal peaks. The first peak appears at $655^{\circ} \mathrm{C}$ and corresponds to the alloy liquidus temperature. In the temperature range $597-594^{\circ} \mathrm{C}$, a solid phase separates from the melt, and in the range $571-564^{\circ} \mathrm{C}$ the eutectic crystallizes.

In a cooling thermogram for an alloy AD33 specimen (Fig. 1b), three typical peaks are also observed. The first peak at $649^{\circ} \mathrm{C}$ is caused by the start of alloy crystallization: formation of $\alpha_{\mathrm{Al}}$ grains, i.e., a solid solution based on aluminum. Therefore, the temperature of $649^{\circ} \mathrm{C}$ corresponds to the alloy liquidus temperature. In the range $622-619^{\circ} \mathrm{C}$ in a thermogram

Yeltsin Ural Federal University (UrFU), Yekaterinburg, Russia; e-mail: k.y.shmakova@ ustu.ru. Translated from Metallurg, No. 2, pp. 85-88, February, 2013. Original article submitted October 29, 2012. 
TABLE 1. Chemical Composition of Alloys AD31 and AD33

\begin{tabular}{|c|c|c|c|c|c|c|c|c|c|}
\hline \multirow{2}{*}{ Alloy } & \multicolumn{9}{|c|}{ Element content, wt. $\%$} \\
\hline & $\mathrm{Mg}$ & $\mathrm{Si}$ & $\mathrm{Ti}$ & $\mathrm{Fe}$ & $\mathrm{Cu}$ & $\mathrm{Mn}$ & $\mathrm{Cr}$ & $\mathrm{Zn}$ & $\mathrm{Al}$ \\
\hline AD31 & 0.6 & 0.4 & 0.04 & 0.1 & $<0.1$ & $<0.1$ & $<0.01$ & $<0.1$ & Rest \\
\hline AD33 & 0.9 & 0.59 & 0.06 & 0.57 & 0.19 & 0.10 & 0.15 & 0.05 & Rest \\
\hline
\end{tabular}
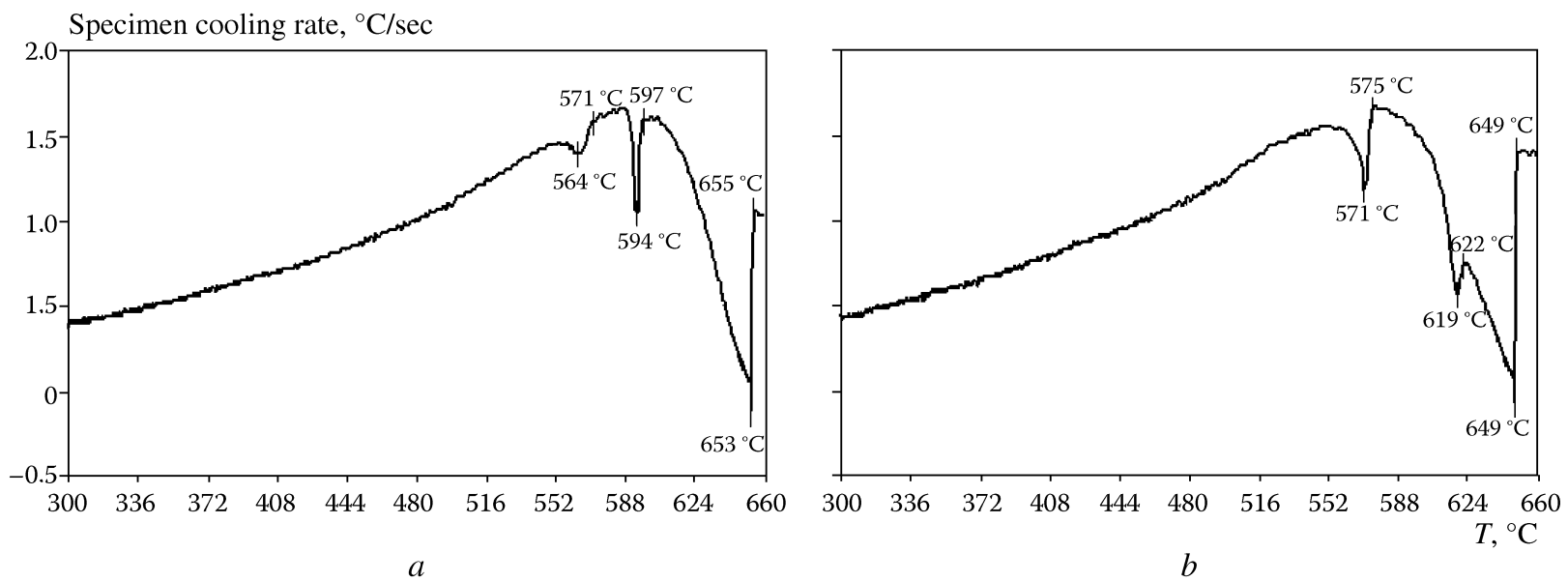

Fig. 1. Thermograms of alloy AD31 (a) and AD33 (b) specimen cooling.

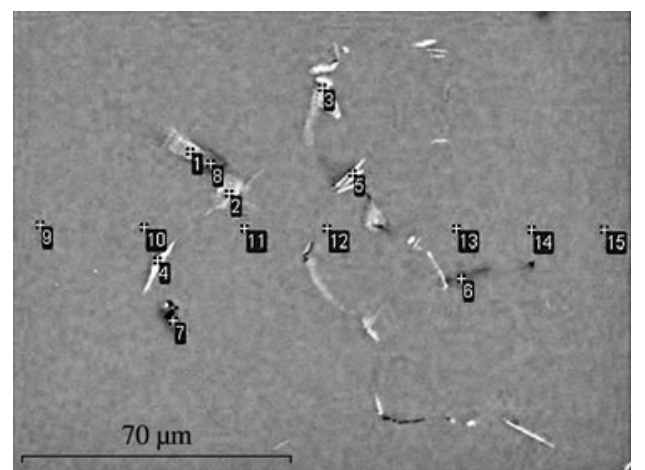

Fig. 2. Alloy AD31 cast specimen microstructure.

there are two exothermic peaks, caused by separation of a solid phase from liquid. In the range $575-571^{\circ} \mathrm{C}$, there is eutectic crystallization.

The original specimens were subjected to electron and x-ray microanalysis. The microstructure of a cast specimen of alloy AD31 is shown in Fig. 2, and results of analyzing the chemical composition of phases are given in Table 2.

The microstructure of a specimen of cast alloy AD31 has two phases (see Table 2). One of these phases is a metastable intermetallic compound $\mathrm{Al}_{17} \mathrm{Fe}_{2} \mathrm{Si}_{3}$ (points 1-5 in Table 2). A second phase is close in composition to the compound $\mathrm{Mg}_{2} \mathrm{Si}$ (points 7-8). The volume fraction of $\mathrm{Al}_{17} \mathrm{Fe}_{2} \mathrm{Si}_{3}$ phase appears to be predominant (see Fig. 2). In grains of aluminum matrix there are only magnesium and silicon in a ratio corresponding to the $\mathrm{Mg}_{2} \mathrm{Si}$ phase (points $10-15$ in Table 2). 
TABLE 2. Local Phase Chemical Composition in AD31 Alloy Specimen

\begin{tabular}{|c|c|c|c|c|c|c|c|c|c|c|c|c|}
\hline \multirow{2}{*}{$\begin{array}{c}\text { Point number } \\
\text { (see Fig. 2) }\end{array}$} & \multicolumn{10}{|c|}{ Element content, wt. } \\
\cline { 2 - 13 } & $\mathrm{Mg}$ & $\mathrm{Al}$ & $\mathrm{Si}$ & $\mathrm{P}$ & $\mathrm{Ca}$ & $\mathrm{Ti}$ & $\mathrm{Cr}$ & $\mathrm{Mn}$ & $\mathrm{Fe}$ & $\mathrm{Ni}$ & $\mathrm{Cu}$ & $\mathrm{Zn}$ \\
\hline 1 & 2.61 & 67.44 & 15.06 & 0.00 & 0.00 & 0.00 & 0.00 & 0.06 & 14.48 & 0.34 & 0.00 & 0.00 \\
\hline 2 & 0.57 & 68.75 & 12.74 & 0.00 & 0.00 & 0.00 & 0.00 & 0.07 & 17.53 & 0.17 & 0.00 & 0.17 \\
\hline 3 & 0.57 & 69.09 & 12.19 & 0.00 & 0.00 & 0.00 & 0.00 & 0.09 & 17.83 & 0.22 & 0.00 & 0.00 \\
\hline 4 & 0.36 & 71.09 & 10.31 & 0.05 & 0.00 & 0.00 & 0.00 & 0.00 & 17.74 & 0.26 & 0.18 & 0.00 \\
\hline 5 & 0.91 & 69.93 & 10.78 & 0.00 & 0.00 & 0.00 & 0.06 & 0.15 & 17.80 & 0.37 & 0.00 & 0.00 \\
\hline 6 & 11.67 & 82.59 & 2.59 & 2.46 & 0.34 & 0.15 & 0.00 & 0.09 & 0.00 & 0.00 & 0.00 & 0.11 \\
\hline 7 & 6.29 & 66.86 & 22.78 & 0.05 & 0.00 & 0.00 & 0.00 & 0.00 & 3.41 & 0.49 & 0.12 & 0.00 \\
\hline 8 & 5.99 & 70.27 & 20.94 & 0.00 & 0.00 & 0.00 & 0.00 & 0.00 & 2.18 & 0.46 & 0.15 & 0.00 \\
\hline 9 & 0.37 & 99.50 & 0.13 & 0.00 & 0.00 & 0.00 & 0.00 & 0.00 & 0.00 & 0.00 & 0.00 & 0.00 \\
\hline 10 & 0.83 & 98.21 & 0.43 & 0.12 & 0.00 & 0.00 & 0.00 & 0.00 & 0.14 & 0.00 & 0.00 & 0.27 \\
\hline 11 & 0.95 & 97.91 & 0.74 & 0.00 & 0.00 & 0.00 & 0.08 & 0.00 & 0.31 & 0.00 & 0.00 & 0.00 \\
\hline 12 & 0.92 & 98.30 & 0.71 & 0.07 & 0.00 & 0.00 & 0.00 & 0.00 & 0.00 & 0.00 & 0.00 & 0.00 \\
\hline 13 & 0.75 & 98.71 & 0.42 & 0.00 & 0.00 & 0.00 & 0.00 & 0.00 & 0.00 & 0.00 & 0.12 & 0.00 \\
\hline 14 & 0.76 & 98.80 & 0.44 & 0.00 & 0.00 & 0.00 & 0.00 & 0.00 & 0.00 & 0.00 & 0.00 & 0.00 \\
\hline 15 & 0.56 & 99.02 & 0.24 & 0.00 & 0.00 & 0.00 & 0.07 & 0.00 & 0.00 & 0.00 & 0.12 & 0.00 \\
\hline
\end{tabular}

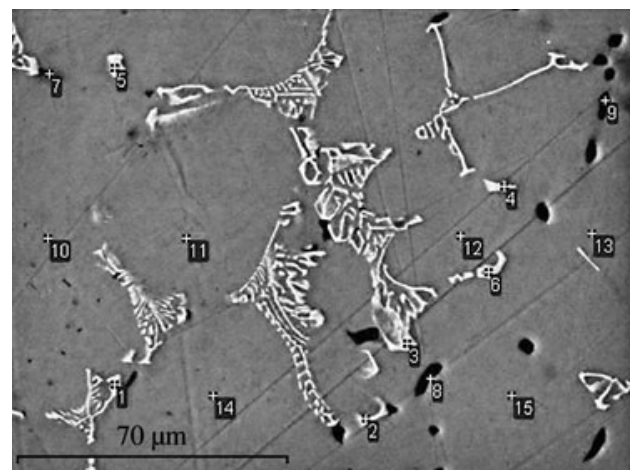

Fig. 3. Alloy AD33 specimen microstructure.

By comparing data of thermal and x-ray microanalyses it may be concluded that the exothermic peak on a cooling thermogram for alloy $\mathrm{AD} 31$ in the range $597-594^{\circ} \mathrm{C}$ is caused by precipitation from interdendritic melt of metastable intermetallic compound $\mathrm{Al}_{17} \mathrm{Fe}_{2} \mathrm{Si}_{3}$ with nonequilibrium crystallization. The exothermic peak in the range $571-564^{\circ} \mathrm{C}$ is caused by crystallization of nonequilibrium eutectic $\alpha_{\mathrm{Al}}+\mathrm{Mg}_{2} \mathrm{Si}+\mathrm{Si}$.

Microstructure is provided in Fig. 3, and in Table 3 there are results of local chemical composition of specimens of phases for an alloy AD33 specimen. There are two phases within the microstructure of this alloy. One of these phases is the compound $\mathrm{Al}_{8} \mathrm{FeSi}$ (points 1-6 in Table 3), which contains about $0.8 \% \mathrm{Cr}, 1.2 \% \mathrm{Cu}, 1.0 \% \mathrm{Mn}$. Precipitates of this phase have 
TABLE 3. Local Phase Chemical Composition in Alloy AD33 Specimen

\begin{tabular}{|c|c|c|c|c|c|c|c|c|c|c|}
\hline \multirow{2}{*}{$\begin{array}{l}\text { Point number } \\
\text { (see Fig. 3) }\end{array}$} & \multicolumn{10}{|c|}{ Element content, wt. $\%$} \\
\hline & $\mathrm{Mg}$ & $\mathrm{Al}$ & $\mathrm{Si}$ & $\mathrm{Ti}$ & $\mathrm{Cr}$ & $\mathrm{Mn}$ & $\mathrm{Fe}$ & $\mathrm{Ni}$ & $\mathrm{Cu}$ & $\mathrm{Zn}$ \\
\hline 1 & 0.30 & 73.28 & 6.68 & 0.06 & 0.59 & 1.12 & 16.53 & 0.00 & 1.14 & 0.31 \\
\hline 2 & 0.25 & 73.46 & 6.81 & 0.00 & 0.80 & 0.94 & 16.27 & 0.11 & 1.36 & 0.00 \\
\hline 3 & 0.33 & 71.19 & 7.53 & 0.00 & 0.89 & 0.84 & 17.75 & 0.11 & 1.35 & 0.00 \\
\hline 4 & 0.34 & 70.36 & 7.20 & 0.00 & 0.96 & 1.30 & 18.70 & 0.00 & 1.14 & 0.00 \\
\hline 5 & 0.26 & 73.75 & 7.07 & 0.00 & 1.42 & 1.16 & 15.35 & 0.00 & 0.99 & 0.00 \\
\hline 6 & 0.47 & 77.59 & 4.79 & 0.00 & 0.59 & 0.72 & 14.65 & 0.11 & 1.08 & 0.00 \\
\hline 7 & 18.03 & 72.69 & 9.28 & 0.00 & 0.00 & 0.00 & 0.00 & 0.00 & 0.00 & 0.00 \\
\hline 8 & 25.32 & 47.05 & 27.38 & 0.00 & 0.00 & 0.00 & 0.13 & 0.00 & 0.12 & 0.00 \\
\hline 9 & 30.86 & 50.04 & 19.10 & 0.00 & 0.00 & 0.00 & 0.00 & 0.00 & 0.00 & 0.00 \\
\hline 10 & 0.90 & 98.92 & 0.18 & 0.00 & 0.00 & 0.00 & 0.00 & 0.00 & 0.00 & 0.00 \\
\hline 11 & 0.90 & 98.36 & 0.44 & 0.00 & 0.18 & 0.00 & 0.12 & 0.00 & 0.00 & 0.00 \\
\hline 12 & 0.84 & 98.10 & 0.41 & 0.00 & 0.12 & 0.14 & 0.18 & 0.00 & 0.21 & 0.00 \\
\hline 13 & 0.81 & 98.39 & 0.45 & 0.00 & 0.00 & 0.09 & 0.11 & 0.00 & 0.16 & 0.00 \\
\hline 14 & 0.83 & 98.33 & 0.36 & 0.00 & 0.07 & 0.00 & 0.00 & 0.11 & 0.14 & 0.16 \\
\hline 15 & 0.84 & 98.66 & 0.33 & 0.00 & 0.00 & 0.00 & 0.00 & 0.17 & 0.00 & 0.00 \\
\hline
\end{tabular}

the shape of Chinese hieroglyphs (see Fig. 3). The second phase corresponds to the compound $\mathrm{Mg}_{2} \mathrm{Si}$ (points 7-9 in Table 3). In grains of aluminum matrix there is predominantly magnesium and silicon in a ratio close to the phase composition $\mathrm{Mg}_{2} \mathrm{Si}$ (points 10-15 in Table 3). Thus, it may be concluded that the isothermal peak in a cooling thermogram for alloy AD33 in the range $622-619^{\circ} \mathrm{C}$ is connected with precipitation from melt of metastable intermetallic compound $\mathrm{Al}_{8} \mathrm{FeSi}$, and the exothermic peak in the range $575-571^{\circ} \mathrm{C}$ is caused by crystallization of eutectic $\alpha_{\mathrm{Al}}+\mathrm{Mg}_{2} \mathrm{Si}$. The reason for the difference in composition of iron-containing phases established in this work and previous studies [3-5] is a marked nonequilibrium nature of crystallization of ingots studied by the authors, produced by a semicontinuous method. As noted in [6,7], under actual crystallization conditions the amount of iron-containing phases may be greater than with crystallization of alloys under equilibrium conditions.

\section{Conclusions}

1. Temperature ranges have been established by thermal analysis for phase transformations occurring during nonequilibrium crystallization of industrial aluminum alloys AD31 and AD33. It has been established that during crystallization of alloy AD33 precipitation from melt of metastable intermetallic phase, enriched with iron and silicon, proceeds at a higher temperature compared with alloy AD31.

2. The composition has been determined by x-ray microanalysis of metastable phases in alloys AD31 and AD33 in a cast condition. In the AD31 alloy matrix there are precipitates of two phases. The first is metastable and has the composition $\mathrm{Al}_{17} \mathrm{Fe}_{2} \mathrm{Si}_{3}$ and acicular form, the second phase is a compound $\mathrm{Mg}_{2} \mathrm{Si}$, which is within the composition of a complex nonequilibrium eutectic: $\alpha_{\mathrm{Al}}+\mathrm{Mg}_{2} \mathrm{Si}+\mathrm{Si}$.Within the matrix of alloy AD33 there are also two phases. One is metastable and the shape of Chinese hieroglyphs, and the composition $\mathrm{Al}_{8} \mathrm{FeSi}$, and the second phase is a compound $\mathrm{Mg}_{2} \mathrm{Si}$, within the composition of nonequilibrium eutectic: $\alpha_{\mathrm{Al}}+\mathrm{Mg}_{2} \mathrm{Si}$. 


\section{REFERENCES}

1. B. A. Baum, Metal Liquids [in Russian], Nauka, Moscow (1979).

2. $\quad$ G. S. Makarov, Refining of Aluminum Alloys with Gases [in Russian], Metallurgiya, Moscow (1983).

3. J. E. Hatch, Aluminum, Properties and Physical Metallurgy: Handbook [Russian translation], Metallurgiya, Moscow (1989).

4. Ya. Polmear, Light Alloys: from Traditional to Nanocrystals [in Russian], Tekhnosfera, Moscow (2008).

5. A. M. Zakharov, Industrial Alloys of Nonferrous Metal. Phase Composition and Structural Components [in Russian], Metallurgiya, Moscow (1980).

6. N. A. Belov, "Quantitative analysis of composition diagrams for $\mathrm{Al}-\mathrm{Fe}-\mathrm{Mg}-\mathrm{Si}$ in the field of aluminum alloys $6 \mathrm{xxx}$ series," Izv. Vyssh. Uchebn. Zaved., Tsvet. Met., No. 1, 43-51 (2005).

7. N. A. Belov, Composition Diagrams for Ternary and Quaternary Systems [in Russian], MISiS, Moscow (2007). 